applications for membership in the society were. received. Professor D. R. Curtiss, of Northwestern University, was reelected a member of the editorial committee of the Transactions, to serve for three years, and Professor L. P. Eisenhart, of Princeton University, to serve on the same committee in place of Professor Dickson for one year.

The twenty-first summer meeting and eighth colloquium of the society will be held at Harvard University, September 4-9, 1916. Two courses of colloquium lectures, each five in number, will be given by Professor G. C. Evans, of Rice Institute, on "Topics from the theory and applications of functionals, including integral equations," and Professor Oswald Veblen, of Princeton University, on "Analysis situs." The year 1916 marks the twenty-fifth anniversary of the broadening out of the society into a national organization and of the founding of the Bulletin. It is proposed to arrange an appropriate celebration of this event at the summer meeting. Some seventy-five of those who were members of the society in the year 1891 have retained their membership through these twenty-five years. It is hoped that the celebration may itself become a notable milestone in the society's history.

Committees were appointed to consider the question of the publication of the Harvard Colloquium Lectures, and to consider in cooperation with committees of other scientific bodies the matter of the classification of technical literature. A committee was also appointed to draw up a list of nominations of officers and other members of the council to be elected at the annual meeting next December.

The following papers were read at this meeting:

Samuel Beatty: "Derivation of the complementary theorem from the Riemann-Roch theorem."

J. F. Ritt: "The resolution into partial fractions of the reciprocal of an entire function of genus zero.",

J. F. Ritt: "Linear differential equations of infinite order with constant coefficients.",

C. J. Keyser: "Concerning autonomous doctrines and doctrinal functions.",

Edward Kasner: “Element transformations of space for which normal congruences of curves are invariant.",

J. H. Weaver: "Some extensions of the work of Pappus and Steiner on tangent circles."

J. L. Coolidge: “New definitions for Plücker's numbers.',

G. C. Evans: “Integral equations whose ker- nels satisfy a certain difference equation in variable differences.',

Dunham Jackson: "An elementary boundary value problem.",

L. P. Eisenhart: “Transformations of eonjugate systems.",

A. A. Bennett: "An existence theorem for the solution of a type of real mixed difference equation."'

A. A. Bennett: "A case of iteration in several variables.",

R. W. Brink: "Some integral tests for the convergence and divergence of infinite series."

Glenn James: "A theorem on the non-summability of a certain class of series.",

F. J. McMackin: "Some theorems in the theory of summable divergent series."

J. R. Kline: "A definition of sense on plane curves in non-metrical analysis situs."

H. B. Fine: "On approximations to a solution of a system of numerical equations.'"

B. H. Camp: "Fourier multiple integrals."

G. A. Pfeiffer: "On the conformal mapping of curvilinear angles.",

G. C. Evans: "Proof of Green's theorem by approximating polynomials.",

A. R. Schweitzer: "On a type of quasi-transitive functional equations.",

J. W. Alexander: "Some generalizations of the Jordan theorem.",

C. E. Wilder: "Expansion problems of ordinary linear differential equations with auxiliary conditions at several points."

E. V. Huntington: "A simple example of the failure of Duhamel's theorem.",

W. F. Osgood: "Note on functions of several complex variables.", F. N. CoLE, Secretary

\section{THE BIOLOGICAL SOCIETY OF WASHINGTON}

THE 553d regular meeting of the society was held in the Assembly Hall of the Cosmos Club, Saturday, March 25, 1916, called to order by President W. P. Hay at 8 P.M., with 40 persons present.

The president called attention to the recent death of Henry Talbott, a member of the society.

Under the heading Brief Notes and Exhibition of Specimens, General Wilcox exhibited lantern slide views of the country along the Mexican border of the United States.

Under the same heading Mr. A. A. Doolittle exhibited a specimen of Amblystoma punctatum from the District of Columbia. 
Dr. O. P. Hay exhibited a mutilated braincase of an elk which had caused certain persons much difficulty to identify; he also showed a remarkably well preserved skull of an extinct horse.

President Hay exhibited a number of lantern slides of biological interest, chiefly of aquatic animals in the vicinity of Beaufort, North Carolina.

Medical Inspector Ames asked if any member present had positive knowledge as to the ability of camels to swim, or otherwise? This question was discussed by several members, but no positive knowledge was forthcoming. He also inquired as to the possible existence of a South American animal with dorsally placed mammæ.

Following the adjournment of the society several members examined a microscopic preparation of a living embryo of Filaria bancrofti obtained by Dr. Lyon from a former inhabitant of British Guiana but for several years resident in the District of Columbia.

The regular program was as follows:

W. P. Hay: "Notes on the Growth of the Loggerhead Turtle," illustrated by lantern slides and chart. Mr. Hay gave an account of two young loggerhead turtles now under observation at the U. S. Fisheries Biological Station at Beaufort, N. C. They are the survivors of a lot of 77 hatched September 9-11, 1912, from eggs obtained from a nest on Bogue Bank about six weeks earlier. When first hatched the average size of the young was: total length $77.3 \mathrm{~mm}$.; length of carapace, $46.2 \mathrm{~mm}$; weight, 20.1 grams.

At the age of three years the survivors measure 493 and $515 \mathrm{~mm}$., in total length; 343.75 and $365 \mathrm{~mm}$., in length of carapace; and weigh 6,690 and 7,967 grams, respectively. The increase in size and weight has been steady and the measurements, which have been taken twice a year, can be plotted as points on a curve. This curve continued indicates that the maximum size of this species, about $1,000 \mathrm{~mm}$. length of carapace, may possibly be obtained in the tenth or eleventh year, and that sexual maturity is probably reached in the sixth or seventh year. This is considerably more rapid growth than has usually been attributed to animals of this kind.

The paper was discussed by Dr. Shufeldt, Dr. O. P. Hay, Medical Inspector Ames, and Mr. Doolittle.

R. W. Shufeldt: "The Restoration of the Dinosaur, Podokesaurus holyokensis.', Dr. Shufeldt gave an historical account of a discussion upon the restoration of the dinosaur Podokesaurus holyoken- sis of Talbot, which took place in the autumn of 1915. This discussion was carried on in correspondence and participated in by Drs. Richard $\mathbf{S}$. Lull and Mignon Talbot, Hr. Gerhard Heilmann, and the speaker. Lantern slide illustration and blackboard demonstration were employed to point out what was held to be inconsistencies in the restoration of this animal, as figured in Dr. Lull's "Triassic Life of the Connecticut Valley" (Fig. 31). Drs. Lull and Talbot contend that the pubic element in the matrix of Podokesaurus holyokensis occupies the position in relation to the other bones of the skeleton that obtained in life. Dr. Shufeldt and Hr. Heilmann controvert this decision by pointing out that all the bones in the slab containing the remains of this dinosaur are far removed from their normal articulations; and that, if the pubic element were articulated as Dr. Lull has figured it, it would have come, in life, forcibly in contact, anteriorly, with the sternal ribs and been a constant menace to the abdominal viscera in various movements of the animal.

R. E. Coker: "A Biological and Fish Cultural Experiment Station," illustrated by lantern slides. Mr. Coker said that since biologists, at least, are generally familiar with the functions of the Fairport Biological Station in the propagation and study of the fresh-water mussels, particular attention was given to the purposes of that station in experiment work relating to the rearing of fishes.

As in horticulture the problems of the nurseryman and those of the fruit grower are distinct, so in fish-culture, and in fish-cultural experiment work there is the phase of the hatchery with its product of fry and fingerling, and that of the fish farm where it is intended to rear fish to adult size in commercial quantities. The Fairport station is concerned with problems of rearing rather than of hatching. The grower of fish has problems similar to those of the stock farmer or the poultry raiser, while in addition he must take thought for conditions affecting the respiration of fish. He can not always regulate the numbers of fishes in his ponds by direct means, but may have to accomplish this end by proper association of species. It may even be necessary to group together species which are to an extent "incompatible."

The problem of the fish pond has its mechanical, physical, chemical and zoological aspects; more especially, however, it is a problem of appropriate vegetation, promotion of food supply, and proper association of species of fish.

$$
\text { M. W. LYON, JR., }
$$
Recording Secretary 